\title{
THE RELATION OF TAXONOMIC METHOD TO AN EXPLANATION OF ORGANIC EVOLUTION
}

\author{
CARL EPLING and WESLEY CATLIN \\ University of California, Los Angeles
}

Received 20.vi.49

THE impact of Charles Darwin's classic, The Origin of Species, has been incalculable. The concept of evolution that he made explicit, and cogently documented, now permeates and gives direction to all biology. Yet, paradoxically, the orientation of his argument, directed as it was toward an explanation of the origin of species, has provided an impediment to study of the causal factors involved in evolution.

Species or specific types had been the focus of attention since the beginning of the Greek development of biology. Within the span of man's memory each kind seemed immutable, and their permanence, accorded religious sanction, had scarcely been challenged. In view of the evidence he had adduced, which could be adequately understood only in terms of an evolutionary hypothesis, it is not surprising that Darwin should have emphasised his refutation of the fixity of species. His monumental contribution, however, was his thesis that evolution proceeds from the natural selection of individual variants. Being handicapped by the lack of genetic evidence, he was forced to frame his argument in taxonomic terminology. He presented extensive data to show that characters which are individual in some instances are subspecific in others, and specific in still others. He also pointed to parallel variation in higher categories. He inferred from this evidence that specific and other typical character results ultimately from the particular differences of individual adaptedness.

Darwin's successors were no more able than he to explain the adaptive process involved in the formation of typical character. Imbued with taxonomic concepts, and impressed by the role of isolation in maintaining specific character for long periods, they regarded the species not only as a taxonomic category but also as an evolutionary unit. This view resulted from the failure to distinguish potential exchange of genetic materials within a species from the actual exchange which alone can be effective in evolution. As a consequence their efforts were directed toward description of the succession of organic types. The origin of a type was explained in terms of change of an earlier type rather than in terms of causally effective individual differences.

This taxonomic conception of evolution still persists. It persists, for example, in the use of categories, such as species, ecotypes, and biotypes, to denote the effective vehicles or so-called dynamic units 
of evolution. It persists also in the use of the term "speciation" as a synonym of evolution, with the implication that the attainment of specific status is the cardinal point in evolution. The limits of species are defined by isolation; but this term and the phrase "the origin of isolating mechanisms" are used ambiguously to denote not only isolation but also effects quite different, which operate far below the specific level. The issue is one of basic orientation. Acceptance to-day of Darwin's basic hypothesis requires the affirmation that evolution proceeds not from the similarities which constitute types and by which the members of categories are recognisable, but from the hereditary differences that adapt individuals to particular environments. This involves the postulate that in the living phase there exist two, and only two, effective vehicles of organic evolution : individuals and mating groups or breeding populations. This hypothesis can be tested only by a study of the adaptedness of individuals that actually interbreed in nature and the offspring they produce, regardless of typical character. Comparisons of species and the development of patterns of typical character provide no test. Taxonomic methods and concepts, which necessarily abstract typical character and overlook particular differences, can do no more than provide evidence that evolution has occurred. They can trace the pattern, but fail to reveal the effective factors and mechanisms. concerned.

So far as a complex and multiform process can be characterised by one phrase, evolution can be said to be change of adaptedness. (This is not to imply, however, that change of adaptive character is a direct response to "need" for change.) Adaptedness is an attribute of individuals. It is a particular relational complex, the fitness of each individual in relation to its particular environment. It is genetic in origin, being determined by gene combination that results from the breeding of individuals sufficiently congruent with one another and with the external environment to survive and reproduce.

Adaptedness is not uniform for two reasons. First, individuals differ as a result of genetic variation, the basic cause of which is mutation. Second, the inorganic phase of the environment is highly varied : the earth's crust, the atmosphere, the sun's light and heat vary from place to place and from time to time. As Heraclitus long since observed, all is in flux. The result is a myriad of local facies of the total environment, a mosaic of factors variously combined and subject to continual change. If this mosaic is to be occupied by living organisms, an assortment of individuals variously appropriate in their adaptedness to these local facies is accordingly required; as these facies change, the organisms adapted to them must change if the race is to persist.

The asexual organism requires for its persistence only one sort of adaptive response, namely, that to its external environment. It can 
achieve change of adaptedness beyond its developmental plasticity (tolerance range, or adaptability, sensu Gause, I942, 1947) only as a result of mutation. The evolutionary resources of clonal organisms are accordingly limited by the rate and character of mutations that occur, and these may be neither adequate nor appropriate to meet the conditions of environmental change. Any device that will permit the accumulation of a varied reserve of mutations without jeopardising survival of the individuals carrying them will prove advantageous to persistence of the group. For amongst such a store a genotype may occur that will be appropriate to a particular environmental change. This device is found in sexual reproduction, which provides for combination in one indivirlual of alleles of different capacities, and hence for future individuals capable of different responses. Sexual reproduction therefore allows a new condition : a capacity of progeny to realise sorts of adaptedness different from those of their parents. This capacity for change of adaptedness of sexually reproducing organisms is adaptability. In this sense, adaptability is not an attribute of individuals, but rather a function of the reservoir of genes contributed by the individuals that actually interbreed. From this reserve are drawn, each breeding cycle, the genotypes that constitute a new generation and a new reserve.

Complete freedom of reproductive association would allow exploration of the totality of potential gene combination. This would have the conceivable advantage of providing individuals preadapted to all possible changes of environment. However, such unlimited combination would result in maladaptation of some or all of the progeny to the existing local environment, to which each reproducing individual is already adapted, and from which the group cannot ordinarily withdraw very far. A limit on the character of genotypes that contribute to a given reserve is accordingly required in order to prevent too great deviation of adaptive character in the progeny. To secure the range of genetic character required for adaptability to change, and at the same time to retain maximal adaptedness of progeny to existing conditions, a balance must be achieved between too much and too little combination, between the consequences of unlimited sexual reproduction on one hand and the adaptive limitations of asexual reproduction on the other. This balance, which is crucial to evolution, is effected through the agency of the breeding population, the limited group of individuals that actually, not only potentially, interbreed. The term breeding population not only denotes a group of reproductively associated individuals but also, by abstraction, connotes the limited and transitory gene reserve from which the genotypes embodied in the offspring are constituted. These interbreeding individuals are the material basis of evolution, and their reproductive association is its vehicle (see Darlington, I939, I940).

The breeding population, accordingly, is the effective evolutionary 
reality, for it and only it can effect change of adaptedness in sexual organisms. The reproductive association and reciprocal interaction of its constituents, and the interaction of their progeny with the external environment, are the epitome of evolution, as Darwin perceived, and as Wright and Dobzhansky, amongst others, have so ably demonstrated. The reality of each breeding population is disclosed solely by its consequences, that is, by its progeny, and not by the possession of common attributes. Let it be remembered also that a breeding population can be drawn from individuals sufficiently divergent in external adaptive character as to be classified as different coexistent species. This is one meaning of introgressive hybridisation. Taxonomically, the breeding population has neither reality nor utility ; it is a genecological concept.

The causal importance of the mating group or breeding population was implied in Turesson's use of the word genecological and his original definition of the ecotype, but was not made explicit. On the contrary, it was obscured by his endeavour to express the interrelation between population and environment by means of typification and classification, rather than by consideration of the adaptive relations of the interbreeding individuals. Turesson originally defined the ecotype (1922, p. I02) as an "ecological unit to cover the product arising as a result of the genotypical response of an ecospecies to a particular habitat." Despite this taxonomic terminology, he at that time, as Gregor says (1947, p. 379), apparently regarded " his ecotype as a relatively homogeneous population separated from neighbouring ecotypes of different heredity by a narrow zone of intergradation." He ascribed the differences of heredity to environmental selection of appropriate genotypes. This was an auspicious beginning for an investigation of the causal factors of evolutionary process.

Conditioned, however, by the pervasive influence of taxonomic concepts in biology, that is, by the tendency to interpret particular relations in terms of types, Turesson apparently lost sight of Darwin's thesis that evolution proceeds from individual differences. $\mathrm{He}$ did not explore further the interrelations of each limited population with its effective environment, as would have been required in order to discover the adaptive factors operating in each case. Nor did he seek to analyse his "particular habitat" in terms of the response of particular genotypes. Instead, he attempted to classify these relations, to typify them. In this effort he necessarily abstracted the similarities of each population, for similarity, not difference, is the basis for assignment to any class. The ecotype accordingly became a type, as its name denotes, a taxonomic category characterised in this instance by physiological rather than morphological attributes. It became eventually the equivalent of the orthodox geographic race or subspecies (Turesson, 1925; Clausen, Keck and Hiesey, 1940). Like these categories the ecotype has been useful for reconnaissance, for description of the mosaic that the evolutionary processes have brought into being. 
It has disclosed the fact that populations vary in their over-all adaptedness in accordance with general gradients of environmental difference. Its virtue is that in focusing attention on the physiological responses of subspecific populations, it has come closer to the factors that determine the adaptedness of genotypes. (The construction of this word is unfortunate. It is used, however, not in the sense of a type, but in the sense of the particular genetic constitution of an individual.) Nevertheless, neither analysis nor description in terms of similarity and typical response will suffice to disclose these factors. This will require other than taxonomic concepts and methods, with reference to both the organism and its habitat.

General comprehension of this requirement has been retarded by a tendency to confuse the taxonomic consequences of isolation with the restrictions on gene exchange that are requisite for adaptability. This confusion is more than a matter of words, as Dobzhansky (I940) has said of the ambiguous use of the term speciation. However, if the term isolation is limited to its literal sense of segregation, involving severance of reproductive relations, its distinction from restriction of gene exchange will be clarified. Isolation can then be employed to indicate specific status as suggested by Dobzhansky in his discussions of speciation (1940) and isolating mechanisms (1937). The agents of isolation, as he pointed out, are numerous and varied, and their effects may differ at different times. They may be elements of either the external or the reproductive environment. They may act independently and yet reinforce one another, producing jointly an effect that no one alone would be capable of. Dobzhansky uses the term speciation to denote this sort of effect. It is the stage in divergence at which restriction of gene exchange has become complete and final. This is the ground for the taxonomic utility of isolation. It is a permanent condition for the maintenance of types. It pertains not to individuals but to groups of individuals and categories. The effect of isolation on evolutionary process, however, is negative ; as Dobzhansky has said, it "slows down evolution." Moreover, isolation may even be a prelude to extinction. For the suppression of intergroup gene exchange, with the attendant reduction of possible preadaptive combinations, will limit each isolate to the resources of its own gene reserves. The asymptote of isolation is the negation of sexual reproduction.

The term "isolating mechanisms" has been employed by Dobzhansky ( 1937) as " a convenient general name for all mechanisms hindering or preventing [italics added] the interbreeding of racial complexes or species." He distinguishes a number of types of agents. within this general category of isolating mechanisms, and states (I94I, p. 256) : "It is an important fact, however, that any agent that hinders the interbreeding of groups of individuals produces the same genetic effect, namely, it diminishes or reduces to zero the frequency of the exchange of genes between the groups." This seems to imply 
that the maintenance of some degree of restricted gene exchange, which may insure adaptability, has the same effect as suppression of gene exchange, which may destroy it. To avoid this confusion, we believe it essential to distinguish between diminished exchange, with its positive effects, and isolation, which tends to be negative with respect to adaptability.

In eliminating intergroup exchange, isolation closes an avenue that earlier provided the possibility of preadaptive combinations. The isolates are thereafter limited to the resources of their constituent and successive breeding populations: their genetic character and size, the reproductive relations already established amongst them, and their relations to the changing environment. Dobzhansky (I94I, p. 255) pointed out that "If life is to endure, gene combinations whose adaptive value has been tested by natural selection must be preserved and protected from [the] disintegration" that would follow unlimited interbreeding. But this protection is secured primarily by the positive effects of agents that operate at a much lower level of organisation than the species. This is borne out by the fact that entities may become and remain sympatric only after gene exchange between them is suppressed sufficiently to allow each to maintain its specific character. Meanwhile, each may have become highly diversified, its parts being harmoniously related to the particular environments in which they occur. To state this concept more clearly and to avoid the equivocal use of the term isolation, we accordingly suggest the following paraphrase : "If life is to be perpetuated by sexual reproduction, a balance must be maintained by restriction of gene combination such as will engender both adaptedness of individuals and subsequent adaptedness of their progeny. This balance is effected by the association of individuals in limited breeding populations. The factors of the effective environment that determine the constituents of each population are to this extent determinants of evolution. The common adaptive characters by which a group is recognised are derived ultimately from those of particular breeding populations by intergroup gene exchange. The limits of these characters may be set by isolation."

The importance of isolation for the evolutionary process lies primarily in the fact that it permits greater diversification of adaptive character by setting limits to gene exchange. In this way it permits occupation of different effective environments in the same area by different genetic systems. It provides for a multiplicity of types. Dobzhansky has accordingly suggested that a premium is put on isolation. This follows logically from the widely accepted generalisation that sympatric species are reproductively isolated. However, this latter is true only of some. Evidence is accumulating to indicate that in many groups of organisms, populations stabilised in type, but still able to exchange genes, can coexist for long periods (for example : Hubbs, I943 ; Wharton, I 944 ; Epling, r947; Stebbins et al., r947 ; 
Hovanitz, I949); they are species even though they are not reproductively isolated. The evidence of their specific status lies in the fact that each maintains its identity despite reproductive contact with one another. Having preserved channels for gene exchange they may, on occasion, form new successful gene systems. These may be formed abruptly, as in the case of alloploidy, or by hybridisation without ploidy (Epling and Lewis, unpublished data) as Stebbins (1942) suggested might be the case; or gradually, as implied by Anderson's concept of introgressive hybridisation (1938). The evolutionary advantage inherent in this possibility of exchange between species is obvious. However, the effectiveness of such species resides not in their specific character nor in their " isolation," but in the character of certain of their constituent individuals which are able as a result of particular reproductive adaptedness to enter a breeding population and thus form new successful genotypes. Accordingly, we suggest that a premium more cogent to evolution is put on the maintenance of a restricted degree of gene exchange, even at the specific level (Epling, 1947). The fact that the genetic systems represented by some species can be preserved for long periods without reproductive isolation suggests that isolation may prove to be no more than a by-product of the reproductive adaptedness and mating character developed in certain groups (see Fisher, 1936). Isolation is not mandatory and may on occasion prove disadvantageous to evolution of the groups concerned.

The exchange of genes between individuals is conditioned in part by environmental factors that determine the distances over which transfer is effective. Related individuals are not uniformly spaced, but tend to be aggregated into communities of varied size and density. All the individuals of a given community do not necessarily exchange genes during one breeding cycle, and the community may accordingly be comprised of more than one effective breeding population. These may not be discrete, and in continuous large populations must be treated as statistical concepts. But, for convenience, these effective populations can be conceived of as discrete, and the exchange of genes between them in the course of time can be regarded as intergroup exchange. A species or its parts can accordingly be regarded as a system of breeding populations, the genetic integration of which varies because of the spatial position and different adaptive responses of its members. The character and extent of population diversity will vary in accordance with the degree of restriction imposed on gene exchange, that is, the amount of "gene flow" between its parts. The effect of intergroup gene exchange is to allow, but not require, adaptive character that arises in one part of a population to spread to another provided that it will enhance, or at least not impair, the environmental and reproductive adaptedness of the latter. As a consequence a given character may become typical of a population. Simpson (1944) has distinguished three styles, or modal aspects, of the evolution of types 
which he has called speciation, quantum evolution and phyletic evolution. Should the character of intergroup exchange be limited so as to result in divergence between parts of a genetic system, such as might occur during great diversification of habitat, speciation in Simpson's sense might then ensue. Should a divergent element of a system be preadapted to an abrupt difference of effective environment, quantum evolution might be expected. Should intergroup gene exchange be facilitated throughout the system, the result might then be phyletic evolution. Recognition of these modes by the variant patterns of evolution that result from them is a function of taxonomic method ; but their recognition does not disclose the process and factors that have produced them. Whatever the mode or pattern, it is still the result of the constitution and particular relationships of each breeding population during this course of change.

Failure to comprehend the limitations of the taxonomic method is nowhere more vividly illustrated than by a recent statement by Goldschmidt (1948, p. 16) that palæontology is "the only science which actually sees parts of evolution in action" [italics added]. The methods of palæotaxonomy and neotaxonomy can do no more than abstract typical characters expressed in the phenotype. They delineate types which have arisen in nature. The homology of similar characters that appear in different types is usually assumed, but can be substantiated by genetic experiment in some instances. Having assumed or ascertained the homology of these characters, the taxonomist can then examine the frequencies with which they appear in similar groups. From the patterns thus determined, he can infer what the course of evolution may have been. One example will suffice.

The plant order Malvales is singularly homogeneous, that is, " natural." It is comprised of six families in which are included 223 genera (including Malva, Gossypium and Hibiscus, to which we shall refer) and more than 2000 species (Edlin, 1935). An ordinal character of considerable taxonomic importance is the leaf. Its total aspect in respect of shape and texture is usually diagnostic of the order and is so uniform that the leaves of one genus may readily be mistaken for those of another. To put it simply, an informed taxonomist looking at a leafy shoot can say with a considerable degree of certainty, "This appears to be one of the Mallows." The prevailing leaf shape in the order is ovate, with a tendency to be notched at the base, that is, heart-shaped. The venation is prevailingly palmate with the principal veins arising at the base of the leaf and diverging like the fingers of a hand. In pinnately veined leaves, a pair of basal veins is usually emphasised. A strong tendency also exists for the margin to be palmately lobed, usually obscurely or incompletely, with three lobes, but sometimes to the extent of producing five (or seven) well-defined lobes, or in some genera, even a digitate leaf with five leaflets.

The homology of this leaf character in different genera and families would doubtless be assumed by most taxonomists. In this instance, the 
assumption has been shown to be well grounded. Stephens (I943, p. 315 ; I945, p. 383) has shown that the same variants as those described above may occur within a species of cotton (Gossypium), some even on the same plant. In some species of cotton the leaves are all unlobed and heart-shaped. Stephens regards this as the juvenile type and has shown that in the course of development " all leaf shapes in the genus pass through, or are potentially capable of passing through three successive phases: (I) an entire (unlobed) leaf phase; (2) a phase in which the leaves at successive nodes become progressively lacinated into five lobes; (3) a climax phase in which leaf shape is stabilized" ( 1945, p. 380). The realised potential, and hence the climax, varies from species to species. This potentiality is genetically controlled, for the climax type that ultimately develops, whether unlobed, lobed, laciniate, or narrow and pinnately veined, is known to be dependent on a series of multiple factors allelic to one another between species (Hutchinson, I934; Harland, I939; Silow, I939). The homology of genes and of typical character between species of Gossypium seems therefore clearly established, just as it has been between Drosophila melanogaster and D. simulans (Sturtevant, I920, I92 I). Furthermore, monogenic control of alternative leaf shape of a similar kind is known in the related genera Malva (Kristofferson, I923) and Hibiscus (Deshpande, I942), and Stephens (1945) has also shown that the developmental pattern of the leaf of Hibiscus rosa-sinensis is similar to that of Gossypium. By virtue of this similarity and probable homology between genera, the inference is drawn that this mode of leaf development had its inception in particular mutations, and that having become characteristic of the order, it now constitutes an ordinal type; or in other words, that types originate from particular differences. Evidences of this kind, provided chiefly by taxonomic methods, substantiated where possible by genetic methods, can be regarded as proofs of evolution; indeed, they are of the kind that Darwin relied on. But, although they indicate the general course evolution has followed, they do not illuminate the processes by which it has been accomplished.

Studies of breeding populations, on the other hand, and of the adaptedness and adaptability of the genotypes they represent, constitute an attack on evolution in process. They are genecological, not taxonomic. They inquire into the changing relations of genotype to genotype, and genotype to environment. They investigate particular causal relationships, not taxonomic types; they are a condition to understanding the ultimate formation of these types.

Formerly based primarily on observation and inference, this inquiry is now amenable to an experimental approach. It has scarcely begun. To prosecute it successfully requires a reorientation of physiology and ecology. The physiology of individuals considered alone, without cognisance of their genotypes, will no longer suffice, nor that of a group of cognate individuals whose relationships are postulated on no 
more than specific resemblances. Nor will the ecology of associated species, which we call communities, suffice except to define the gross character of the habitat. The orientation of the future requires as its objective a study of the physiology and ecology of mating groups and the progeny that issues from them. Investigations in these fields will acquire meaning to the degree that the adaptedness and adaptability of the organisms concerned are taken as a guide.

It is necessary now to ascertain the mechanisms responsible for the assortment of genotypes in nature : their faculties of migration and the limits on establishment imposed by the character and rhythm of the particulars of the environment with which they may perchance react. This is to say that we must discover the mechanisms that determine what shall be the constituent individuals of successive breeding populations. For the variables that limit or increase reproductive and external adaptedness and the range of tolerance of both will determine the adaptive character of the breeding population and the adaptability of succeeding populations. This is the core of the evolutionary problem.

Two formidable technical barriers obstruct the approach to it: our limited knowledge of organisms whose genotypes, as encountered in nature, can be identified by appropriate markers; and inadequate methods for studying the effective environment.

The organisms of the sort required, for example, are those whose genotypes can be identified and studied as to their reactions. A close approach to this requirement is known now in certain species of Drosophila. In this organism the chromosomal inversions, by suppression of recombination, tend to preserve the integrity of the genotype to which the chromosome in question contributes (Dobzhansky and Epling, I948). At the same time, the inversion, and hence the genotype, so far as it is preserved intact by the inversion, can be identified by the visible banding of the salivary gland chromosomes. Thus two genotypes, somewhat approximate in constancy, but differing in adaptive values (Heuts, I947 ; Epling et al. unpub.), can be combined and their interactions analysed. Advantageous and even unique as this material is, it is still no more than an approximation to the ideal. Whether more facile material can be found or constructed remains to be ascertained.

Assessment of the external environment is of equal importance, for what is being investigated is a complex particular relationship between the living and nonliving. To this end, attention must bear on the effective environment. By this we mean the particular external factors that, by their selective action on the genotypes presented to them, determine those that come to reproductive maturity and hence may become the constituents of any given breeding population. The effective environment is accordingly a conceptual complement of the effective breeding population. A simple example will illustrate our meaning. Drosophila pseudoobscura is active throughout the year in 
the Sierran foothills, but the life span of an individual is measured in days. The seasonal changes in frequency of the carriers of different chromosomal types, which are known to differ in adaptive character, show clearly that, as the seasons progress, each succeeding population is subject to different daily rhythms, both physical and biotic (Dobzhansky, I947). The adaptive relations that determine the constituents of one seasonal population do not determine those of another. Furthermore, certain species of a perennial Delphinium also occur in this region. Depending on the weather, these may remain dormant for several years, or at most may form a rosette of leaves. Flowering occurs only when a certain limiting threshold is passed. This threshold appears to be a physiological response subject to individual variation. Variation is further evidenced by the fact that the flowers of some individuals may wither before they have matured their seeds. The breeding population of a given year is accordingly determined by a particular association of variables rather than by "the environment" in a gross or constant sense. Even though Drosophila and Delphinium occur in the same locality, the fact is also obvious that the effective environment of one may bear little relation to that of the other.

The procedure for determining external environmental factors with present methods is primarily taxonomic, that is, to circumscribe a locality and ascertain the association of variables that characterises it. The adaptedness of the organism being investigated is then interpreted in terms of the environmental category thus created. Recognising that small differences of topography, for example, may modify such associations, the attempt is sometimes made to particularise them by reducing the locality to a "microenvironment," usually in a spatial sense. Although this device is initially useful in an exploratory way, the particular variables effective in determining the reproductive association of members of a breeding population and the survival of their progeny must still be investigated in particular causal terms. Tools are required that will somehow discriminate these relationships.

Similarities of phenotype may overlay differences of individual response that are crucial to change of adaptedness. Taxonomic methods and concepts can deal only with similarities of phenotype and must perforce overlook individual differences. Such methods, while adequate for recognition of the patterns already evolved, are inadequate for a study of evolutionary processes, for this must necessarily rest on knowledge of individual differences within the mating group. Accordingly, it is necessary now to recognise and reject the tendency that Gregor (1947, p. 390) has described as "the almost subconscious desire to resolve intra-specific variation into categories capable of being absorbed into the orthodox taxonomic system," such as subspecies, ecotypes and biotypes, and turn to an investigation of particular causal relations. The conceptual and 
technical barriers are formidable. When they have been surmounted, then and only then, shall we begin to comprehend the processes that result in change of adaptedness.

\section{SUMMARY}

The orientation of evolutionary research is still predominantly taxonomic and concerned with the delineation of typical character, its development, and its subsequent localisation by reproductive isolation. These studies are essential to a proof of organic evolution. But, contrary to tacit or explicit assumptions often made, knowledge of typical character does not, and cannot, disclose the processes that effect change of adaptedness or the development of typical character itself. These processes can be disclosed only by study of the particular relations that exist between the individuals of an effective breeding population and its effective environment.

\section{REFERENCES}

ANDERSON, E. 1949. Introgressive Hybridization. New York.

CLAUSEN, J., KECK, D. D., AND HIESEY, W. M. 1940. Experimental studies on the nature of species. Carnegie Inst. Publ. 520.

Darlington, C. D. 1939. The evolution of genetic systems. Cambridge.

DARLington, C. D. 1940. Taxonomic species and genetic systems. In The Nerw Systematics. Oxford, pp. I37-I59.

DESHPANDE, R. B. 1942. Inheritance of leaf-lobe in Hibiscus cannabinus L. Indian 7 . Genetics and Plant Breeding, 2, 181-182.

Doвzhansky, TH. 1937. The genetic nature of species differences. Amer. Nat., 7I, 404-420.

DöZhansky, тH. 1940. Speciation as a stage in evolutionary divergence. Amer. Nat., 74, 312-321.

DOBZHANSKy, тн. 194I. Genetics and the origin of species, 2nd ed. New York.

DOBZHANSKY, TH. 1947. Evol., I, I-I6.

DOBZHANSKY, TH., AND EPLING, c. 1948. The suppression of crossing over in inversion heterozygotes of Drosophila pseudoobscura. Proc. Nat. Acad. Sci., 34, I37-I 1 I.

EDLIN, H. L. 1935. A critical revision of certain taxonomic groups of the Malvales. New Phytologist, 34, I-20, 122-143.

EPLING, C. 1947. Natural hybridization of Salvia apiana and S. mellifera. Evol., I, 69-78.

FISHER, R. A. 1936. The measurement of selective intensity. P.R.S., B, 12I, 58-62.

GAUSE, G. F. 1942. The relation of adaptability to adaptation. Quart. Rev. Biol., I7, 99-I I 4 .

gause, G. F. 194.7. Problems of evolution. Trans. Conn. Acad. Arts and Sci., 37, 17-68.

GOLDSCHMIDT, R. 1948. Ecotype, ecospecies, and microevolution. Experientia, 4, $465-485$.

GREGOR, J. W. 1947. Some reflections on intraspecific ecological variation and its classification. Trans. and Proc. Bot. Soc. Edin., 34, 337-391.

HARLAND, s. c. 1939. The genetics of cotton. London.

HEUTS, M. J. 1947. Influence of humidity on the survival of different chromosomal types in Drosophila pseudoobscura. P.N.A.S., 33, $210-213$. 
Hovanitz, w. 1949. Interspecific matings between Colias eurytheme and Colias philodice in wild populations. Evol., $3,170-173$.

HUBBS, C., AND MILLER, R. R. 1943. Mass hybridization between two genera of cyprinid fishes in the Mohave Desert, California. Papers Mich. Acad. Sci. Arts and Letters, $28,343-378$.

hutchinson, J. B. 1934. The inheritance of leaf shape in Asiatic Gossypium. $\mathcal{F}$. Genet., 28, 437-513.

KRISTOFFERSON, K. B. I923. Monohybrid segregation in Malva species. Hereditas, $4,44-54$.

silow, R. A. 1939. The genetics of leaf shape in diploid cottons, and the theory of gene interaction. F. Genet., 38, 229-276.

simpson, G. G. 1944. Tempo and mode in evolution. New York.

STEBBINS, G. L., JR. 1942. The role of isolation in the differentiation of plant species. Biol. Symp., 6, 21 7-233.

STEBBINS, G. L., JR., MATZKE, E. B., AND EPLING, C. 1947. Evidence of hybridization in a population of Quercus marilandica and Q. ilicifolia. Evol., I, 79-88.

STEPHENS, s. G. 1943. A genetic survey of leaf shape in New World cottons. A problem in critical identification of alleles. F. Genet., 46, 313-330.

STEPHENS, s. G. 1945. Some observations on leaf shape expression in the Malvaceæ. Amer. Nat., 7.9, 380-384.

sturtevant, A. H. Ig20. Genetic studies in Drosophila simulans I. Genetics, 5, 488-500.

StURtevant, A. H. 1920. Genetic studies in Drosophila simulans II. Genetics, 6, $43-64$.

Sturtevant, A. H. 1921. Genetic studies in Drosophila simulans III. Genetics, 6, $179-207$.

TUREsSON, G. 1922. The genotypical response of the plant species to the habitat. Hereditas, 3, $211-350$.

TURESSON, G. 1925. The plant species in relation to habitat and climate. Hereditas, $6,147-236$.

WHARTON, L. T. 1944. Studies in the genetics of Drosophila. Interspecific hybridization in the repleta group. Univ. Texas Publ. 4445, 173-193. 